\title{
Can Mindfulness Help People Implement a Growth Mindset? Two Field Experiments in
}

\section{Hungary}

Gábor Orosz $^{1 *}$, Gregory M. Walton ${ }^{2}$, Beáta Bőthe ${ }^{3}$, István Tóth-Király ${ }^{4}$, Amelia Henderson ${ }^{2}$, and Carol S. Dweck ${ }^{2}$

${ }^{1}$ Atelier SHERPAS - Equipe URePSSS, UFR STAPS de Lievin, Université d'Artois, France

${ }^{2}$ Department of Psychology, Stanford University, Stanford, USA

${ }^{3}$ Département de Psychologie, Université de Montréal, Montréal, Canada

${ }^{4}$ Department of Psychology, Concordia University, Montreal, Canada

*Corresponding author:

Dr. Gábor Orosz, 9 rue du Temple - BP 10665, 62030 ARRAS CEDEX

e-mail: gaborosz@gmail.com

Author Note

We thank the participating schools and Réka Török, Judit Hegedüs for their help in data collection. Thanks to the kind and supportive communities of the Dweck-Walton lab at Stanford University and the Social Interventions lab at Eötvös Loránd University. Thanks to István Winkler's Lab at the Hungarian Academy of Sciences for making it possible to prepare the audio recordings and to David Yeager, Eric Smith, Camilla Griffiths, Kata Sik, Csilla Czirják, Dávid Farkas, Elizabeth Weitz, Hae Yeon Lee, Kris Evans, Gregg Muragishi, Tom Dee, and Juan Ospina for their valuable help and advice in the present work. This work was supported by the Hungarian Research Fund (FK 124225). We thank the Schmidt Foundation for supporting the first author at the time of this work. 


\title{
Can Mindfulness Help People Implement a Growth Mindset? Two Field Experiments in
}

\section{Hungary}

\begin{abstract}
Does holding a growth mindset prevent people from experiencing potentially negative or maladaptive thoughts and feelings following academic setbacks? Not necessarily: In our Hungarian sample, a culture high in negative affect, three-fourths of people who endorsed a growth mindset at a maximum level nonetheless reported at least sometimes being judgmental of themselves and ruminating about setbacks. Thus, in two field experiments performed in Hungary, we incorporated mindfulness elements into an existing growth-mindset intervention (Yeager et al., 2019). These elements focused on accepting but distancing the self from negative thoughts and feelings in response to setbacks. This enhanced growth-mindset treatment significantly raised semester grades among university $(N=251$, Study $1, d=0.29)$ and reported grades among high school students $(N=3,095$, Study $2, d=0.17)$. A growth-mindset intervention alone also raised GPA with an effect size similar to the effect sizes found in prior research (Study 2); however, this effect did not consistently reach significance across models with the present sample size. Although just a first step, the present studies suggest the value of incorporating mindfulness elements to help people manage a tendency toward negative and counterproductive reactions that may remain even following a mindset intervention.
\end{abstract}

Keywords: academic achievement, educational psychology, growth mindset, mindfulness, wise interventions 


\section{Can Mindfulness Help People Implement a Growth Mindset? Two Field Experiments in}

\section{Hungary}

In recent years, researchers have increasingly demonstrated the potential of interventions that alter beliefs or theories about the self to address diverse social issues, including school achievement and health (see Dweck \& Yeager, 2019; Walton \& Crum, 2020; Walton \& Wilson, 2018). Such belief changes are thought to help people make sense of everyday negative experiences in more adaptive ways (Walton \& Brady, 2020a). For instance, social-belonging interventions convey that worries about belonging are normal in an academic transition but improve with time. In so doing, they aim to prevent students from seeing everyday adversities in school as evidence of a global lack of belonging (Walton \& Cohen, 2011). Stress-mindset interventions convey that stress can reflect your body getting ready to take on a challenge, and so aim to prevent people from viewing stress as only negative and undermining of performance and health (Crum, Salovey, \& Achor, 2013). And growth-mindset of intelligence interventions convey that intelligence can grow with hard work, effective strategies, and the appropriate help of others. They thus aim to prevent students from perceiving academic setbacks as evidence of fixed inability (Blackwell, Trzesniewski, \& Dweck, 2007; Yeager et al., 2019). Yet, even if people fully endorse a relevant belief system, might they nonetheless experience contrary thoughts and feelings when they experience a meaningful setback? If so, would it help to supplement an intervention aimed at promoting an adaptive belief system with efforts to help people manage negative thoughts and feelings when setbacks arise?

Here, we explore this question in the context of a growth mindset. We pair an established growth-mindset intervention with an approach inspired by mindfulness interventions, with the 
goal of helping people manage counterproductive failure-induced thoughts and feelings more effectively (Creswell, 2017; see also Strick \& Papies, 2017).

\section{Growth Mindset and Negative Thoughts in Response to Setbacks}

A fixed mindset of intelligence is the belief that intellectual abilities are fixed and unchangeable, whereas a growth mindset is the belief that intellectual abilities can be developed. Mindsets provide an overarching meaning system that can influence how people make sense of and respond to diverse situations and challenges. In a fixed-mindset of intelligence system, with its focus on measuring ability, the occurrence of difficulty or setbacks can be seen as signs of low ability (Blackwell et al., 2007; Dweck \& Yeager, 2019; Robins \& Pals, 2002), engendering greater risk for negative affect in the face of academic struggles. In contrast, in a growth-mindset system, difficulty and setbacks tend to be seen as more natural parts of learning, with setbacks tending to elicit greater effort or new strategies (Burnette et al., 2013; Dweck, Chiu, \& Hong, 1995; Nussbaum \& Dweck, 2008).

In this way, individual differences in mindsets can predict learning and achievement over time (Blackwell et al., 2007). Moreover, it is now established that interventions to convey a growth mindset can raise school achievement (Aronson, Fried, \& Good, 2002; Blackwell et al., 2007), especially for struggling students (Paunesku et al., 2015), including in large-scale preregistered replication studies (Yeager, Romero, et al., 2016; Yeager et al., 2019).

Although the two mindsets have sometimes been understood in either-or terms (i.e., an individual has one mindset or the other), people may commonly have access to both fixed- and growth-mindset belief systems. Indeed, fixed mindsets may be reinforced in ubiquitous cultural contexts, such as high-stakes testing situations that purport to measure intellectual abilities (Steele \& Aronson, 1995), common praise practices (e.g., "You're so smart!” Gunderson et al., 
2013; Kamins \& Dweck, 1999; Mueller \& Dweck, 1998; Pomerantz \& Kempner, 2013), academic programs (e.g., "Gifted and Talented” programs), and an organizational focus on talent (e.g., Murphy \& Dweck, 2010). Moreover, many everyday experiences, such as struggle, failure, or criticism, may serve as environmental "triggers" that cause people to wonder if they are smart or not (Dweck, 2015). Yet potential conflicts between the endorsement of a growth mindset in the abstract and such fixed-mindset "triggers" have not been explored. We propose that even people who fully endorse a growth mindset can be vulnerable to counterproductive thoughts and feelings consistent with a fixed mindset when confronted with relevant triggers, such as a personally important setback.

To test this supposition, a pilot study assessed the endorsement of a growth mindset and self-reported thoughts in response to failure among adults in Hungary, our country of focus. Participants in this pilot study $\left(N=504 ; \mathrm{M}_{\mathrm{age}}=40.2\right.$ years; education: $18.1 \%$ primary, $27.2 \%$ secondary, $49 \%$ higher education) were representative in terms of gender, age, level of education, and type of residence (i.e., city, town or village) among Hungarians who use the Internet at least once a week. Of primary interest were participants who endorsed a growth mindset at the maximum level (strongly disagreed with all three fixed-mindset items, $N=65$ ). We examined their reports of tendencies that reflect fixed-mindset thinking in which failures reflect on the self and its competence.

Strikingly, the great majority of growth-mindset individuals nonetheless reported experiencing some significant negative self-relevant thoughts in response to failure (see Table S1). For instance, $83.1 \%$ reported that, at least sometimes, "I ruminate on what happened and it takes up all of my energy" and $72.3 \%$ reported at least sometimes, "I'm judgmental with myself and I'm occupied by the thought what is wrong in me." Overall, the link between the 
endorsement of a growth mindset and self-reported negative thoughts after failure in this sample was negative but weak, $r(504)=-0.11, p=0.01$. The results suggest that even people who endorse a growth mindset can experience negative thoughts following failure (see SM 1).

\section{The Hungarian Context}

The Hungarian educational context is a particularly interesting one in which to explore our research question. According to major cross-cultural surveys, Hungarians are prone to negative ways of thinking, including about themselves. For instance, Eurostat $(2013,2014)$ finds that Hungary has the highest proportion, among the 28 European Union countries, of people who experience depressive symptoms (i.e., persistent sadness, loss of interest in activities that one normally enjoys, or inability to carry out daily activities) and the third lowest score on overall life satisfaction. Most years between 1960 and 2000, the suicide rate in Hungary was the highest in the world, with the most established risk factors being affective disorders. Since 2000, the suicide rate in Hungary has declined but, although many factors were assessed, only an increase in antidepressant prescriptions consistently predicted this decline (see Rihmer, Gonda, Kapitany, \& Dome, 2013). Thus, negative reactions to setbacks may be especially accessible in Hungary. Perhaps in this context in particular, even for those who endorse a growth mindset, this belief may not fully stem the flow of negative thoughts and feelings when setbacks occur.

Understanding responses to setbacks is all the more important in Hungary, because Hungarian students have below average math and science performance and are in the lowest $20 \%$ in achievement motivation compared to other OECD countries (OECD, 2017). Any intervention that can improve resilience and performance in such a context would be especially welcome.

\section{Growth Mindset with Mindfulness Elements}


Mindfulness was developed as a strategy to help people manage general negative thoughts and feelings more effectively. It encourages people to be aware of their experiences (thoughts and feelings) in the present moment in a non-judgmental way (Creswell, 2017; Zenner, Herrnleben-Kurz \& Walach, 2014). In past research, mindfulness has often been taught in eightweek in-person meditation programs (e.g., mindfulness-based stress reduction, Kabat-Zinn, 1982). Such programs can reduce participants' anxiety and stress and increase their well-being and cognitive functions (Chiesa, Calati, \& Serretti, 2011; Eberth \& Sedlmeier, 2012; Hofmann, Sawyer, Witt, \& Oh, 2010). However, these interventions do not focus on specific contexts or events that can cause negative thoughts and feelings or the particular content of these thoughts and feelings. Instead, mindfulness is taught as a general approach to unwanted or disruptive thoughts and feelings (cf. Papies, Barsalou, \& Custers, 2012). In contrast, the present adaptation focuses specifically on negative thoughts and feelings people could have in response to academic setbacks. This strong focus allowed us to deliver the mindfulness element far more briefly than in typical past mindfulness trials (under 10 minutes), and to embed this element in an existing online growth-mindset module (Yeager et al., 2019).

In the context of the growth-mindset program, we focused on four mindfulness-related elements in response to challenges or failures. Students learned, first, that it is normal to experience negative thoughts and feelings in challenging situations such as after setbacks, (i.e., normality of having negative experience, Feldman, Hayes, Kumar, Greeson \& Laurenceau, 2007; Lindsey \& Creswell, 2017; Neff et al., 2005). Second, they were encouraged to recognize such thoughts and feelings (Feldman et al., 2007) without blaming or judging the self (i.e., acceptance of thoughts and feelings, Kabat-Zinn, 2003; Lindsey \& Creswell, 2017). Yet these thoughts, although normal and accepted, were not represented as valid or true. Third, the intervention 
emphasized stepping back and observing this experience from outside the self by noticing that they are "just feelings and thoughts," passing events in the mind (i.e., decentered perspective, Creswell, 2017; Papies, Pronk, Keesman, \& Barsalou, 2014; Shepherd \& Cardon, 2009). We aimed to further facilitate decentering by asking students to give a name to their negative thoughts and feelings (e.g., "well, well, well, you are here again Angry Malfoy”; see Dweck, 2016), and encouraging students to separate this experiencing part of the self (which may suffer following setbacks) from the analyzing part of the self (which is learning to interpret the situation and their experience in a growth-mindset manner) (i.e., self-distancing, Kross, Ayduk, \& Mischel, 2005; Kross et al., 2014). Fourth, students were encouraged to let such thoughts and feelings go without fighting them (Lindsey \& Creswell, 2017). All these elements were interwoven with the growth-mindset narrative and not marked as separate content.

As a first step, Study 1 tested whether an approach combining growth mindset and mindfulness could raise achievement (compared to a control group) over an academic semester among university students facing significant academic challenges. Study 2, which included a larger sample of high school students, added a growth-mindset-only treatment and examined effects as a function of prior performance, following past research (Paunesku et al., 2015; Yeager et al., 2019). Our primary question was whether the treatment that integrated mindfulness with growth mindset would be successful in raising semester achievement for students in this culture facing academic challenges. Independently, as a reference point, Study 2 assessed the effectiveness of a growth-mindset-only treatment in our sample (with the knowledge that achieving the statistical power to discriminate between the mindset alone and the mindfulness with mindset conditions would likely require a sample size that was beyond what was possible). 
In addition to our primary goal of synthesizing growth mindset and mindfulness, this research contributes to the accumulating knowledge about online, scalable growth-mindset interventions in diverse social and educational contexts. To date, this research has been conducted primarily in the United States (Paunesku et al., 2015; Yeager, Romero, et al., 2016; Yeager, Walton et al., 2016; Yeager et al., 2019) with some exceptions (Norway: Bettinger, Ludvigsen, Rege, Solli, \& Yeager, 2018; Peru: Outes, Sánchez, \& Vakis, 2017). Here we examine a Hungarian context which, as noted above, may be particularly interesting in terms of its tendency toward negative affect.

\section{Effect Sizes in Growth-Mindset Interventions}

Following past research testing online growth-mindset and related interventions in different school contexts, it is possible to anticipate an effect size on grade-point-average ranging from a tenth (0.10) of a standard deviation (Yeager et al., 2019) through a quarter (0.25) of a standard deviation (Yeager, Walton, et al. 2016 Experiment 3) to perhaps even larger due to the addition of the mindfulness component. Study 1 tested the effect of an online growth-mindset plus mindfulness intervention on grades in a university context, a combination that has not been examined in past research. Study 2 featured students in much more diverse school contexts, including participants from 48 different high schools across Hungary. Following past research with similarly diverse high school contexts (Yeager et al., 2019), in Study 2 we anticipated a lower effect size, but still in the range of a tenth (0.10 SD) to a fifth (0.20 SD) of a standard deviation among lower-performing students.

In controlled laboratory contexts, improvement in performance of this magnitude, such as on an immediate behavioral outcome, would not be striking. But gains in this range from a short, scalable treatment on grades earned months later are substantial, especially for adolescents. For 
example, a gain of 0.24 standard deviations is the same as what can be expected on nationally normed tests from a year of work on reading among ninth-grade students (see Hill, Bloom, Black, \& Lipsey, 2008). Likewise, the benefits of large and costly "structural” interventions with adolescents_ — such as a year with an excellent vs. average teacher, or a smaller class size — seem to top out at about 0.20 standard deviations (Hanushek, 2011). This is particularly the case when the sample is diverse, when the study has a rigorous randomized controlled design, and when examining real-world outcomes over time, such as grades, which are influenced by many factors beyond the treatment (Kraft, 2020).

Given the anticipated effect sizes, in both studies we aimed to recruit as many students as possible. In Study 1, we made significant efforts to reach all first-year students at the given university, for example, inviting students who missed the class in which the intervention was delivered to fill out the online materials. In Study 2, upon consulting with lawyers specializing in Hungarian laws protecting minors' data, we found that personal data including name, e-mail address, date of birth, etc. could not be asked of high school students through our planned (Qualtrics based) online data gathering methods, thus making it impossible to reach students who missed a session and making it more difficult to match students across sessions and follow-up. Lacking such identifiers, we developed a workaround but anticipated nontrivial random attrition due to matching errors between the two experimental sessions and the follow-up at which the primary outcome was assessed. We prepared for this issue by reaching out countrywide to as many high schools and students as possible. Such attrition may be considered a necessary cost of testing an online mindset intervention with minors in this cultural context. Thus, in an important sense, the strengths and limitations of the two studies complement each other. In Study 1, official academic record data were available from a single university with a smaller number of 
participants. In Study 2, although the sample drew from multiple high schools and was larger and more diverse, the legal constraints led us to expect attrition and forced us to rely on self-reported academic outcomes. Finally, we note that although we report the study with university students as Study 1 and that with high school students as Study 2 for ease of exposition, we actually conducted the studies in reverse order. Thus, some secondary measures assessed in Study 1 are not included in Study 2.

\section{Study 1: Growth Mindset with Mindfulness Among University Students}

In addition to the primary outcome of semester grades, Study 1 examined whether growth mindset with mindfulness would affect psychological measures linked in past research to growth-mindset interventions (e.g., Yeager, Romero et al., 2016): reduced fixed-mindset beliefs, adaptive attributions for academic setbacks, and increased challenge-seeking. In addition, we explored the way the intervention changed novel measures assessing students' intentions to use mindfulness strategies in response to academic setbacks, their confidence in their ability to do so, and their beliefs in the fixedness or malleability of mindfulness. The intervention was delivered to students in the first semester of university using materials adapted from Yeager and colleagues (2019). Because our primary goal was to provide an overall test of the efficacy of the mindset plus mindfulness intervention in the Hungarian cultural context, and because the participant sample was limited, Study 1 did not include a growth-mindset condition without mindfulness.

\section{Method}

\section{Participants and University Context}

First-year students $\left(N=251, M_{\text {age }}=23.31 ; S D_{\text {age }}=6.72 ; 31.90 \%\right.$ female; $99.60 \%$ Caucasian $)$ at a Hungarian public university, which aimed to prepare students for public service, took part. Students were enrolled in a mandatory class and, although participation in the study was 
voluntary, no enrolled students in attendance chose not to participate. Enrolled students not present were contacted and asked to complete the intervention online on their own. Seven students did not provide an appropriate Student ID, which prevented us from obtaining their academic records. Four did not finish the materials but were retained in the analyses.

The university was not elite. The admissions rate was $28.90 \%$, which is less selective than the national average across all universities in Hungary (22.77\%). In national rankings, the university ranked the $23^{\text {rd }}$ out of 45 institutions. Most students were first-generation university students; $58.6 \%$ did not have a parent with a post-secondary education. Based on these indicators we expected that a significant portion of first-year students at this institution might not have a background that could help ensure a smooth transition from high school to university. The context was well-suited for our research in another way, since students at the university were under considerable academic pressure: If they did not successfully complete all of their assignments in the first semester, they would have to reimburse a significant amount of their tuition and housing allowance. For these reasons, we expected that most students would react negatively to setbacks and would benefit from the growth-mindset with mindfulness treatment.

Power was limited by the number of students enrolled in the course and who agreed to take part. The obtained sample of 251 provides $80 \%$ power to detect an effect of $d=0.36(\alpha=0.05$, two regression coefficients) and $61 \%$ power to detect an effect of $d=0.25$, the latter of which was quite near the range of predicted effect sizes. Of course, we could not anticipate fully what effect size we would find, as Study 1 is the first test of a mindfulness with growth-mindset intervention or any mindset intervention in a Hungarian university context. As noted, Study 2 will provide a larger sample.

\section{Procedure and Intervention Content}


The intervention was delivered midway through the first semester. The intervention was adapted from materials developed for the National Study of Learning Mindsets (Yeager et al., 2019), primarily to adjust for age and higher education level without removing any content. The full intervention in Yeager et al. (2019) lasted approximately 50 minutes over two sessions. The current intervention including the mindfulness content was administered in one session lasting 59.4 minutes. All materials and measures were translated into Hungarian and back-translated following Beaton, Bombardier, Guillemin and Ferraz (2000). The study was approved by the ethics committee of the first author's university.

The exercise was represented as an online workshop in which students could learn about the brain. The growth-mindset content was built around a key analogy: that the brain is like a muscle in that it can grow stronger by taking on challenging schoolwork. It vividly conveyed that intellectual abilities can be improved if one works hard, tries new strategies, and asks for help when it is needed, and underscored the growth mindset theme with compelling testimonials from other students and with interactive exercises (see Yeager et al., 2019, for a complete description). The mindfulness content comprised nine additional screens interspersed among the growthmindset content. It focused on the themes mentioned earlier: normalizing setback-induced thoughts and feelings; recognizing and accepting them without according them truth; distancing and decentering from them; and letting them go. Importantly, this content encouraged students to try out mindfulness strategies in response to academic setbacks, it represented these strategies as ones they would be capable of using, and it tacitly suggested that setback-relevant mindfulness strategies could be developed over time. Both the mindfulness content and the growth-mindset content were interactive, and included active written reflection tasks (see Figure 1). 
The control condition was identical to Yeager et al.'s (2019). It focused on the functioning of the brain rather than the nature of intelligence (the control material lasted 57.4 minutes). Prior research finds that this content is at least as interesting as the treatment content (Yeager, Romero, et al., 2016). It also had the same structure and type of interactive reflection tasks. Following informed consent, random assignment was accomplished automatically in real time by the survey software; therefore, all staff were blind to condition.

Figure 1. Sample material from the mindfulness portions of the growth-mindset with mindfulness intervention.

\section{Recognizing and letting go of the negative feelings or thoughts}

- Negative thoughts are just thoughts. These thoughts do not mean that you cannot learn and grow.

-When you experience negative thoughts, you can decide what to do about them.

- The first step is to recognize: "This is just a thought."

- Step back and let it go.

Notes. Later, among other interactive elements, students were asked to "help us explain this to other students" by giving their advice to "incoming first year students" in 2-3 sentences.

\section{Measures}

Fixed mindset of intelligence. Two items assessed fixed mindsets (e.g., "You have a certain amount of intelligence, and you really can't do much to change it."; 1=Strongly disagree, 6=Strongly agree; Dweck et al., 1995; Orosz et al., 2017) immediately before and immediately after the intervention. The items on the pre- and post-treatment measures were averaged 
(separately) such that higher values correspond to more fixed mindsets $\left(r_{\text {pre }}=0.66, r_{\text {post }}=0.59\right.$, $p<0.001)$.

Challenge-seeking. Following Yeager, Romero et al. (2016) and Yeager et al. (2019), after completing the intervention or control materials, students were told that they might have the opportunity to do math problems at the end of the session and were asked if they would rather do easy problems that they would probably get right "without having to think very much" or hard problems on which they could "learn something new" but on which they would "probably get most of the problems wrong." Choosing the hard problems indicated challenge-seeking (see SM 2).

Additional psychological measures. We also assessed a number of additional psychological measures immediately after the treatment. We report these in the supplement because we were pilot testing new items and/or they were of secondary theoretical interest here (see SM 3.1-4). However, for the purpose of the present paper, the most important of these examined different aspects of mindfulness: students' (1) trait mindfulness (4-items, e.g., "I try to notice thoughts without judging them," Feldman et al., 2007); (2) mindfulness behavioral intentions (7-items, e.g., "How much will you try in this semester to be understanding with yourself if you do something wrong during your studies"); (3) mindfulness self-efficacy (7-items, e.g., "If you are honest with yourself, in this semester how often would you be able to be 'understanding with yourself' if you do something wrong during your studies”), and (4) fixed mindset about mindfulness (8-items, e.g., "No matter what you do, you can't change how much you accept your thoughts and feelings"). The latter three measures were newly developed for this study. 
Grade-point average (GPA). The university provided students' official grades in each of their courses over the first semester, a four-month period, on a five-point scale (1=worst grade $\sim E / F$ in the US grading system, $5=$ best grade $\sim A$ in the US grading system). We focused only on grades received from lecture courses, not seminars, because lecture courses are obligatory and involve considerable work and study while seminars can be voluntary, involve little work and no exams, and may base grades primarily on attendance. Prior (the past year of high school) GPA was self-reported as official records were not available.

\section{Results}

Random Assignment. Random assignment to condition was successful. No variable assessed before the intervention differed significantly by condition (age, gender, parental education and pre-intervention fixed intelligence mindset beliefs, and GPA in the last semester of high school), all $p s>0.28)$.

Fixed Mindset Beliefs. After controlling for pre-intervention fixed-mindset beliefs, the intervention reduced fixed mindset of intelligence beliefs as compared to the control group, $\beta=-$ $0.26, t(244)=-2.37, p=0.019, d=0.26$. See Table 1 .

Challenge-Seeking. The intervention significantly increased challenge seeking. The percentage of students who preferred to do hard problems on which they could learn a lot, versus easy problems they could get right, rose from $39.49 \%$ in the control condition to $64.84 \%$ in the intervention condition, $\chi^{2}(1)=14.89, p<0.001, V=0.25$.

First-Semester GPA. An OLS regression analysis, reported below, tested the effects of condition on first-semester university GPA controlling for GPA in the prior year of high school (which itself was a significant predictor, $\beta=0.27, t(242)=2.43, p<0.001, d=0.27$ ). As gender did not predict post-intervention GPA, $p>0.22$, we did not control for it. 
Table 1. Descriptive statistics (Study 1).

\begin{tabular}{lccccc}
\hline & $\mathrm{N}$ & Missing & Range & $\begin{array}{c}\text { Control Condition } \\
\text { Raw Mean }(S D) \text { or } \%\end{array}$ & $\begin{array}{c}\text { Growth-Mindset with } \\
\text { Mindfulness } \\
\text { Condition } \\
\text { Raw Mean }(S D) \text { or } \%\end{array}$ \\
\hline $\begin{array}{l}\text { Pre-intervention semester } \\
\text { (high school) GPA }\end{array}$ & 251 & 0 & $3-5$ & $4.14(0.60)$ & $4.06(0.63)$ \\
$\begin{array}{l}\text { Post-intervention, first } \\
\text { semester (university) GPA } \\
\text { (raw) }\end{array}$ & 244 & 7 & $1-5$ & $3.07(0.96)$ & $3.32 *(1.02)$ \\
$\begin{array}{l}\text { Pre-intervention fixed } \\
\text { mindset of intelligence }\end{array}$ & 250 & 1 & $1-5$ & $2.14(0.84)$ & $2.21(1.05)$ \\
$\begin{array}{l}\text { Post-intervention fixed } \\
\text { mindset of intelligence } \\
\text { (raw) }\end{array}$ & 247 & 4 & $1-5.5$ & $2.25(0.94)$ & $2.01 *(1.11)$ \\
$\begin{array}{l}\text { Post-intervention challenge } \\
\text { seeking }(\% \text { choosing a hard } \\
\text { problem over an easy one) }\end{array}$ & 247 & 4 & $0-1$ & $39.49 \%$ & $64.84 \% * *$ \\
\hline$* p<0.05, * * p<0.01$ & & & & & \\
\hline
\end{tabular}

The effect of the growth-mindset with mindfulness treatment was significant, $\beta=0.29$, $t(241)=2.36, p=0.019, d=0.29$. Students earned higher semester grades in the intervention condition $(M=3.34, S E=0.09)$ than in the control condition $(M=3.05, S E=0.08)$, see Figure 2.

Figure 2. First semester GPA by intervention condition (Study 1).

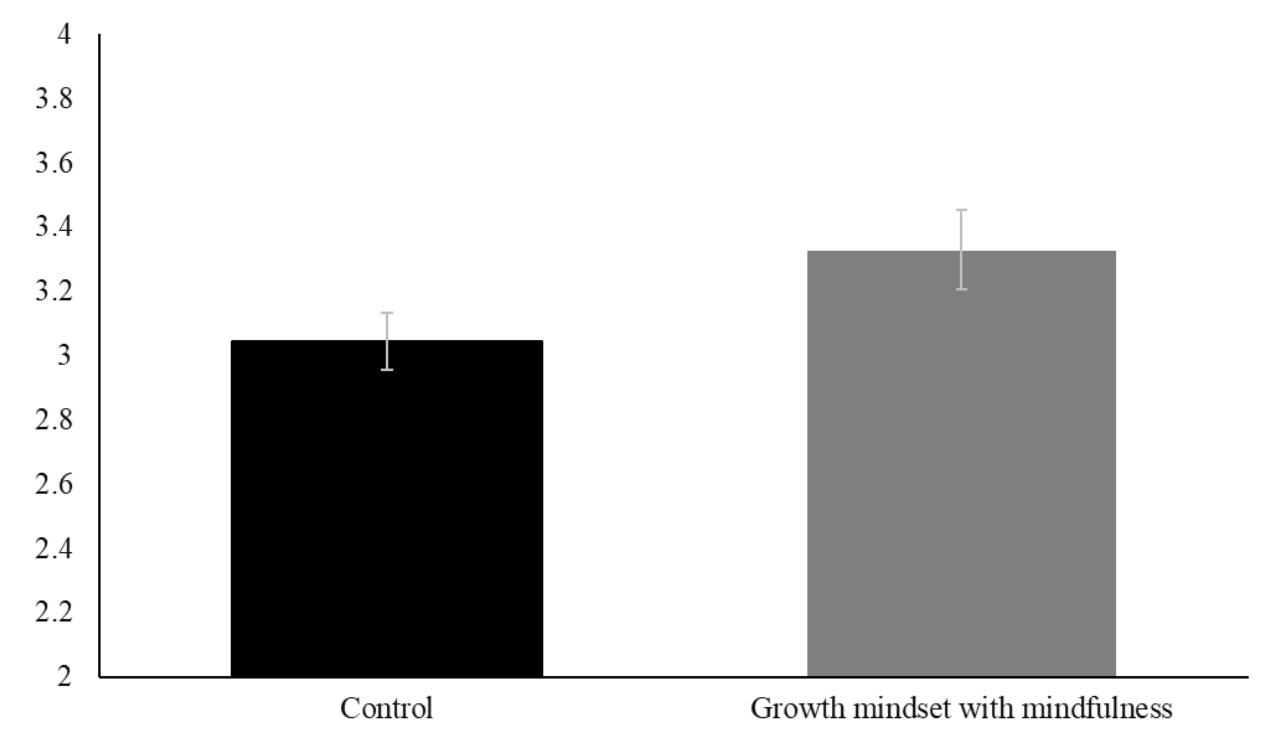


Notes: Means are adjusted for prior GPA. Error bars represent standard errors. The y-axis represents approximately 2 SDs. The Hungarian grading system is based on a five-point scale (1=worst grade $\sim E / F$ in the US grading system, $5=$ best grade $\sim A$ in the US grading system).

Additional psychological measures. These measures are reported in full in the supplement, see SM 3.5. However, the results for the mindfulness measures were revealing. There was no effect of condition on trait mindfulness, $t<1$. Nonetheless, consistent with the theoretical premise of our work that mindfulness can be understood in domain-specific ways, the measures examining students' intentions to use mindfulness in the context of academic setbacks and their perceived self-efficacy for doing so both showed treatment effects. Students reported more intentions to be mindful in response to academic setbacks in the treatment than control condition, $t(244)=3.91, p<0.001, d=0.48$. They also reported more confidence in their ability to be mindful in response to academic setbacks with treatment, $t(245)=3.85, p=0.0002, d=0.48$. Beyond these context-specific measures, the treatment also led students to view the capacity for mindfulness as more malleable, or less fixed, $t(242)=2.46, p=0.015 d=0.31$.

Moreover, students' fixed mindsets about mindfulness related to the gains in GPA $t(236)=-2.81, p=0.005, d=0.18$. In exploratory mediation models, we observed a marginally significant pattern whereby the reduction in fixed mindsets about mindfulness with treatment partially mediated the effect of the growth-mindset with mindfulness intervention on improvement in GPA, $\beta_{\text {indirect }}=0.05, z(238)=1.78, p=0.076$ (for details see SM 3.5.).

Study 1 suggests that mindfulness elements can be integrated effectively with a growthmindset intervention and, moreover, when this was done it raised course grades in a cultural and educational context quite different from the United States. In Study 2, we adjusted the materials for Hungarian high school students and implemented the treatment on a randomized basis with a larger and more diverse sample. We also took advantage of the larger sample to include a 
growth-mindset only condition alongside the growth-mindset with mindfulness treatment and the control condition.

\section{Study 2: Growth Mindset with Mindfulness Among High School Students}

In order to test the two treatments separately (Growth Mindset, Growth Mindset with Mindfulness) and compare them to the control group, we recruited a larger sample, and readapted the intervention for a younger sample from a broad variety of high schools. Following prior tests of online growth-mindset interventions with diverse adolescents in the United States (Paunesku et al., 2015; Yeager, Romero, et al., 2016, Yeager et al., 2019), we expected improvements in GPA would be most evident among students with lower prior academic performance. Such students not only have greater opportunities for GPA gains (no ceiling effect for them) but may also be most likely to experience academic setbacks that trigger negative thoughts and feelings and, therefore, to benefit from adaptive beliefs and strategies relevant to these thoughts and feelings. As in Study 1, in addition to the primary outcome of GPA, we explored students' fixed versus growth mindset beliefs about intelligence and their challenge seeking.

Our main goal was to test each treatment relative to the control condition. Although the comparison between the two treatments is also important, this was not our primary question. Indeed, Experiment 2 is not well powered to detect this difference, as this comparison would require a sample size far beyond the present opportunity. For instance, $80 \%$ power to detect an increase in an effect size from $d=0.10$ observed in past research (Yeager et al., 2019) to $d=0.15$ would require between 12,561 and 29,720 participants depending on the number of predictors. Our sample size was also affected by the strict Hungarian regulation of children's personal data, which, as noted earlier, created challenges in matching students to academic outcomes. Thus, we 
focus on the test of both treatments against the control, particularly among lower-performing students (Yeager et al., 2019).

\section{Method}

\section{Participants}

To provide as much statistical power as possible, we invited 60 public high schools across Hungary to participate (e.g., through invitation emails, phone calls, career counselling networks, school psychologist networks, educational NGOs, secondary school connections of the university). A total of 47 schools, in 13 of Hungary's 19 counties $(10.5 \%$ of the schools from the capital), agreed to take part. We received a total of 3,323 student responses. Dropping duplications, 3,096 unique $9^{\text {th }}$ grade students $\left(M_{\text {age }}=14.82, S D_{\text {age }}=0.92\right)$ were randomly assigned to the three conditions. There were thus 64.5 unique students per school, reflecting the fact that many of the schools were small and rural. To obtain $80 \%$ power to detect an effect of $0.1 \leq d \leq 0.2$ requires a sample of 3,142 to 787. For the CONSORT diagram, see SM 4.

\section{Procedure}

The intervention was translated and back-translated from the original materials and pretested with Hungarian high school students regarding culture-specific aspects such as pictures of U.S. students and quotations from well-known Americans like Michelle Obama. The Hungarian students reported that they liked these materials and did not find them inappropriate; therefore, we kept them without modification. The intervention included every slide from the original materials of the National Mindset Study (Yeager et al., 2019). As the materials were also read aloud (students could also listen what they read), the Hungarian voiceover was carried out with professional actors in a professional audio studio. 
Figure 3 depicts the timeline. Following Yeager and colleagues (2019), the intervention was delivered in two sessions as high school classes are only 45 minutes long. Therefore, it was necessary to identify participants' condition from the first session to give them the correct condition materials in the second section. It was also necessary to identify participants to merge data across the two sessions and with post-test results (e.g., reported GPA).

Figure 3. Timeline.

Semester 1

\begin{tabular}{|c|c|c|c|c|}
\hline $\begin{array}{c}\text { September } \\
\text { Semester begins }\end{array}$ & 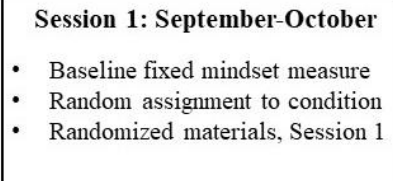 & $\begin{array}{l}\text { Session 2: November-December } \\
\text { - Randomized materials, } \\
\text { Session } 2 \\
\text { - Fixed mindset measure } \\
\text { - Challenge seeking measure }\end{array}$ & $\begin{array}{c}\text { January } \\
\text { Semester ends }\end{array}$ & $\begin{array}{l}\text { Follow-up: March } \\
\text { - } \text { End of semester GPA } \\
\text { - } \quad \text { Fixed mindset measure }\end{array}$ \\
\hline
\end{tabular}

Note: Only primary measures are indicated. Semester 1 ended at the end of January.

As noted above, Hungarian law prohibits asking children for personal data, including name, date of birth, name of parent, or official ID number. Therefore, to deliver the appropriate condition-specific material to students in Session 2, following randomization to Session 1, we gave students at the beginning and at the end of Session 1 one of three condition-specific geometric forms (a red circle, blue square, and green triangle) and asked them to remember it. When students began Session 2, they were asked which of the three geometric forms they had been shown previously. This choice determined the materials they saw in Session 2. Thus, if students did not choose the correct geometric form, they would be misallocated to condition. See the CONSORT diagram for more details (see SM 4, Figure S3).

To merge data across sessions, we asked participants to provide their initials, day of birth (e.g., 17, without month or year), and kindergarten symbol; in Hungary, all students are supposed to attend kindergarten and each kindergartener in a class has a unique symbol; $95 \%$ of pretesting participants could recall their kindergarten symbol. We asked these questions at the beginning of each session and at the follow-up, so we could match data across sessions. During data cleaning, 
we identified students by their initials, kindergarten symbol, and day of birth, and then examined whether they received the same condition material in Session 2 as in Session 1, as intended.

Despite these efforts, because some participants were present in Session 1 but not in Session 2 or in the follow-up, or because they were missing data on identifiers, some students could not be matched between Session 1 and Session 2 or between Sessions 1 or 2 and the follow-up (see SM 4).

\section{Final Samples}

We used two overlapping samples for analyses: Sample 1 included students whose data from the follow-up — when outcome measures were obtained — could be matched with data from Session 1 regardless of whether their data could be matched with Session $2\left(N_{\text {Sample }} 1=1,959\right.$, $63.3 \%$ of the full sample). Sample 2 included students whose responses could be matched across both sessions and the follow-up; that is, they received and finished the assigned intervention $\left(N_{\text {Sample 2 }}=1,501,48.5 \%\right.$ of the full sample $)$ and provided the follow-up data. Sample 1 provides an estimate of treatment effectiveness in settings with students who may have been misallocated or were absent in Session 2. It also includes a larger sample (and thus potentially more power) but this misallocation in or absence from Session 2 could reduce impact. Sample 2, in which there were no misallocations or missing sessions, estimates effectiveness when the interventions are fully implemented. It is important to keep in mind that the two samples are overlapping subsets of the same students, not independent samples such as those used for replication. For a more detailed description of Samples 1 and 2, see Figure 4 and SM 4.

Both samples had somewhat more girls than boys (Sample 1: 60.4\% female; Sample 2: $59.9 \%$ ) and were homogenous in ethnic background, reflecting the Hungarian population (Sample 1: 3.2\% belonged to a racial-ethnic minority group; Sample 2: 3.7\%). A small majority 
of students attended academically oriented "grammar" high schools, which are designed to prepare students for college (Sample 1: $56.6 \%$, Sample 2: $56.3 \%$ ); the rest attended vocational schools, which are designed to prepare students for jobs without post-secondary education (Sample 1: 43.4\%, Sample 2: 43.7\%). Most students did not have a parent with a post-secondary degree (Sample 1: 57.8\%, Sample 2: 60\%). The protocols for this study were approved by the institutional ethics committee of the first author's university.

Figure 4. Comparison between Sample 1 and Sample 2

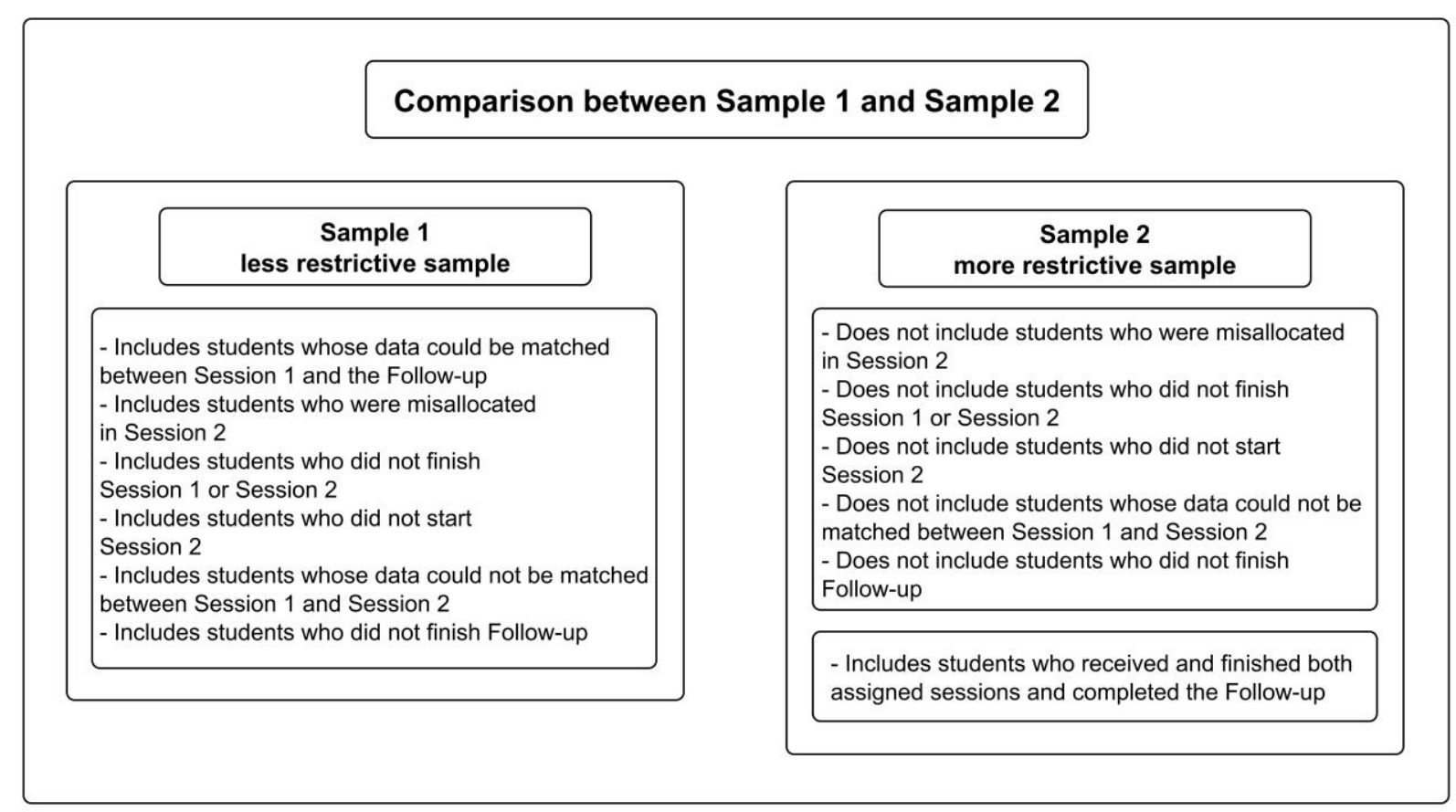

Note: Neither sample included duplicated records. Students who began the randomized material more than once were considered based on their first allocation

\section{Measures}

Demographic measures. Age, gender, parental education, race-ethnicity were assessed before Session 1.

Fixed mindset of intelligence. The same two items assessed fixed mindsets as in Study 1. Fixed mindset was assessed before Session 1, after Session 2, and in the follow-up. 
Grade-point average (GPA). Because Hungarian law prohibits obtaining official grade data for high school students, students self-reported the overall GPA they had earned in the academic year immediately prior high school (in the post-test of Session 1) and the grades they earned in each of their courses in the first semester of high school (in the follow-up). GPA in the first semester of high school was calculated as the average of students' self-reported grades in the most important classes, those necessary for graduation: mathematics, Hungarian grammar, Hungarian literature, history, and foreign language. Based on the meta-analysis of with 44,176 high school students, actual and self-reported GPA were very strongly correlated ( $\mathrm{r}=0.82$; see Kuncel, Credé, \& Thomas, 2005). Therefore, we can assume that self-reported GPA deriving from the most important classes can be a reliable outcome measure of students' academic achievement.

Challenge seeking: Make-a-math worksheet. We included a broader behavioral measure of challenge-seeking than in Study 1, which was designed to yield a continuous measure of math-related challenge-seeking (see Yeager et al., 2016). It was administered at the end of Session 2. Consulting with math teachers, we created 12 pages of math problems. Each page presented six math problems. Two of the problems on each page were easy and (accurately) labeled "Not very challenging," two were moderately difficult and labeled "Somewhat challenging," and two were difficult and labeled "Very challenging." Students were asked to choose two from each set of six problems, which they were told they could work on in the available time after the online program. The number of "very challenging" minus the number of "not very challenging" problems selected was the outcome of interest (ranging between -24 and 24). 
Additional psychological measures. As in Study 1, we administered a number of additional measures to understand our sample and for exploratory analyses. However, because Study 2 was conducted before Study 1, we did not yet have the novel mindfulness measures (mindfulness behavioral intentions, mindfulness self-efficacy, and fixed vs. malleable mindsets about mindfulness). For the measures assessed, see SM 5.1-4.

\section{Results}

\section{Preliminary Analyses}

Random assignment to condition was successful. There was no difference by condition on any demographic or academic baseline measure, including age, gender, parental postsecondary educational status, minority status, type of school (grammar vs. vocational), fixed mindset beliefs, or prior GPA (all $p s>0.057){ }^{1}$

We examined overall attrition (independent of condition) and differential attrition (dependent on condition) in both samples. Regarding overall attrition, students retained in both samples, as compared to those not retained, had better prior grades (Sample 1: $t=5.68, p<0.001$; Sample 2: $t=5.54, p<0.001$ ), were younger (Sample 1: $t=-6.68, p<0.001$; Sample 2: $t=-6.41$, $p<0.001$ ), were more likely to be girls (Sample 1: $z=7.36, p<0.001$; Sample 2: $z=5.70, p<0.01$ ) or racial-majority students (Sample 1: $z=-4.01, p<0.01$; Sample 2: $z=-3.89, p<0.001$ ), and were more likely to attend grammar schools (Sample 1: $z=3.38, p<0.001$; Sample 2: $z=-3.01, p<0.01$ ). Other demographic and academic characteristics did not predict overall attrition rate.

We assessed differential attrition by testing interactions with condition assignment. Importantly, in both subsamples, no interaction with any demographic measure (age, gender, and

\footnotetext{
${ }^{1}$ The only trend was that marginally more students had parents without a post-secondary degree in the growth mindset with mindfulness intervention than in the control condition.
} 
parental post-secondary educational status) or academic characteristic (prior grades, type of school) reached significance (all $p \mathrm{~s}>0.11$ ).

\section{Analytic Strategy}

Using OSL regression models, we examined the effect of the intervention conditions and their interaction with prior GPA. Rather than categorizing students as low- or high-achievers (e.g., Yeager et al., 2019), we treated prior GPA as a continuous variable to obtain more nuanced information about its potential moderating role.

Following Yeager, Romero, et al. (2016), we examined interactions between the two treatment conditions and prior GPA and simple effects of condition at \pm 1 SD ("Base models" in Table 2). The second set of models used multilevel modeling and controlled for a random intercept for school as well as a random slope of condition by school ("Adding random school effect models" columns in Table 2). The third set added gender (0: male), and parents' postsecondary degree status (0: no post-secondary degree among parents) as covariates (“Adding demographics" columns in Table 2). Each model was conducted on both samples.

In examining psychological outcomes, however, for the sake of simplicity and clarity, we focus on the more comprehensive Sample 1 and report Sample 2 results only when they differ meaningfully (which was rare).

\section{Primary Analyses}

GPA. Overall, the results showed that the growth-mindset with mindfulness intervention produced consistent significant gains in GPA among lower-performing students (e.g., -1 SD in prior performance) relative to the control condition across samples and models. The growthmindset alone intervention produced gains in GPA for lower-performing students comparable in magnitude to the gains found in past research but these effects reached only marginal 
significance in the present, smaller, sample. Next, we discuss the results for each treatment in more detail.

In both samples, as compared to the control condition, the growth-mindset with mindfulness intervention led to 0.15 higher GPA for lower-performing students, with an effect size ranging between 0.17 and 0.19 standard deviations across models (See Table 2). Descriptively, this effect is somewhat larger than the gains observed for lower-performing students in past studies of online growth-mindset alone interventions. Using similar methods and analyses, Paunesku et al. (2015), found a 0.10 standard deviation mean gain in GPA among academically at-risk students; Yeager, Romero et al. (2016) found a 0.10 standard deviation mean gain; finally, Yeager et al. (2019), with a nationally representative U.S. sample, found a mean gain of 0.11 standard deviation in GPA among lower performers.

In line with prior results and our expectations, among higher-performing students (one standard deviation above prior GPA mean), there were no gains in GPA from the growthmindset with mindfulness intervention in any sample or model (all $p s>0.25$ ). In Sample 1, the interactions between the growth-mindset with mindfulness treatment (vs. control) and prior GPA was consistently significant $\left(p_{\text {base model }}=0.009, p_{\text {random school model }}=0.007, p_{\text {plus demography model }}=0.044\right)$. In the smaller Sample 2, the interaction did not reach significance ( $p_{\text {base model }}=0.104, p_{\text {random school }}$ model $\left.=0.096, p_{\text {plus demography model }}=0.084\right)$, see Table 2 and Figure 5.

Next, we examined the effect of the growth-mindset intervention alone, first in Sample 1. For lower-performing students at baseline, the growth-mindset intervention alone raised GPA but this reached significance only in the base model, $\beta=0.13, \mathrm{SE}=0.06, t=2.05, N=1853, p=0.040$. Controlling for the random school effect, and for demographics, the effect became either marginal or non-significant. Similar results obtained in Sample 2. However, the observed effect 
sizes $(0.10 \leq d \leq 0.13)$ are within the range observed in past research, as noted above

$(0.10 \leq d \leq 0.11)$. There was no treatment effect for higher-performing students (+1 SD) in any model (all $p s>0.33$ ). The interaction with prior GPA was marginal in one test and nonsignificant in five.

Figure 5. Gains in first-semester high school GPA in standard scores relative to the control group among Hungarian high school students from Sample 1 as a function of prior GPA and treatment condition (Study 2).

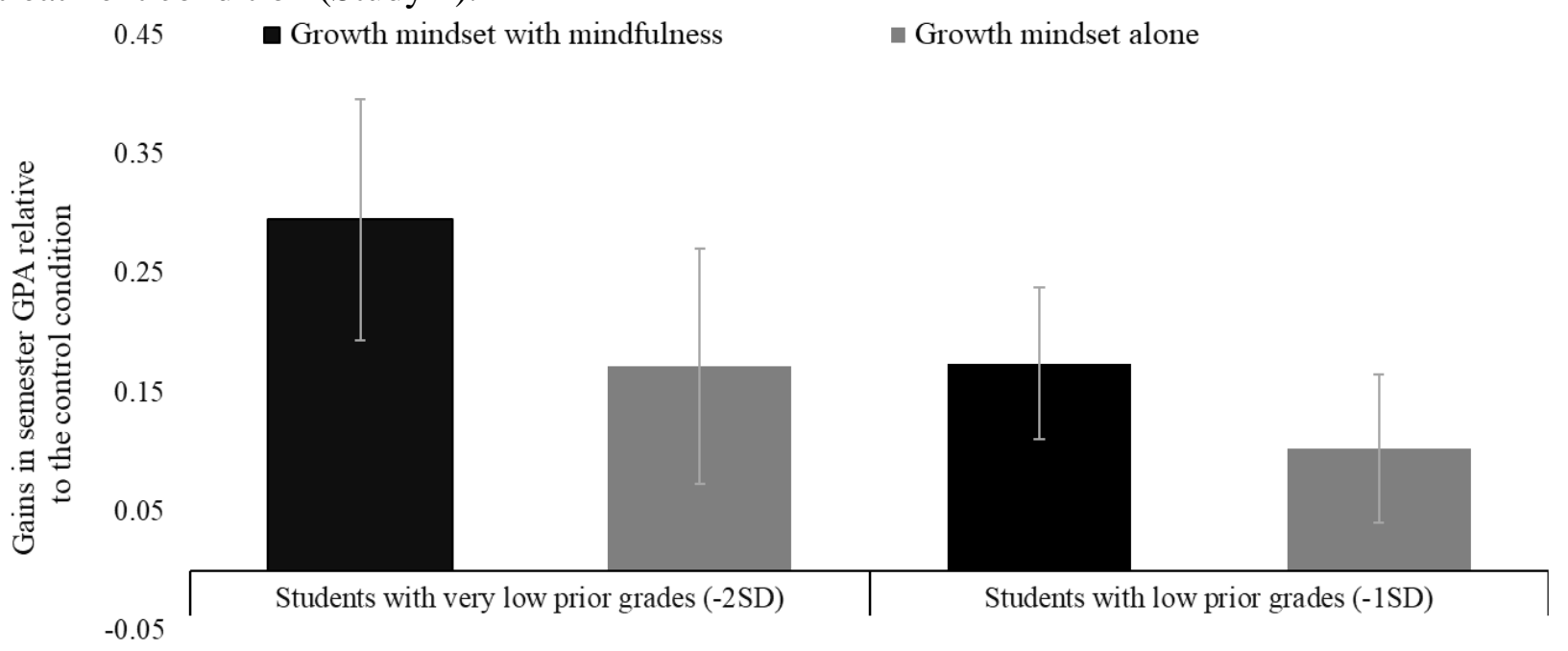

Notes: Means are adjusted for random school effect, prior GPA, gender, and whether a parent had earned a post-secondary degree and centered to the mean of prior GPA at -1 SD of its mean (right panel) and at -2 SD of its mean (left panel).

\section{Psychological outcomes}

As noted, analyses of psychological outcomes examine Sample 1. We report Sample 2 results where they differ.

Fixed mindset about intelligence. Replicating past research (e.g., Yeager, Romero et al., 2016), in Sample 1, controlling for baseline fixed mindset, the growth-mindset intervention reduced fixed mindsets about intelligence immediately after Session $2, \beta=-0.20, \mathrm{SE}=0.05, t=-$ 3.74, $N=1,607, p<0.001$, as did the growth-mindset with mindfulness intervention, $\beta=-0.19$, $\mathrm{SE}=0.05, t=-3.53, N=1,607, p<0.001$. 
Examining the same outcome in the follow-up survey approximately four months after treatment, in Sample 1, controlling for baseline fixed mindset, only the growth-mindset intervention produced significant lasting belief change, $\beta=-0.13, \mathrm{SE}=0.05, t=-2.63, N=1,955$, $p<0.001$. The effect of the growth-mindset with mindfulness treatment was not significant, $\beta=-$ 0.06, $\mathrm{SE}=0.05, N=1,499, t=-1.07, p=0.29$. However, in Sample 2, both the growth-mindset alone, $\beta=-0.18, \mathrm{SE}=0.06, N=1,499, t=-3.02, p<0.01$, and the growth-mindset with mindfulness intervention reduced students' fixed mindset about intelligence at follow-up, $\beta=-0.12, \mathrm{SE}=0.06$, $t=-2.13, N=1,499, p<0.05$.

Challenge seeking. The behavioral challenge-seeking task was administered immediately after the Session 2 treatment or control materials. In Sample 1, both the growthmindset treatment, $\beta=0.23, \mathrm{SE}=0.06, t=3.76, N=1646, p<0.001$, and the growth-mindset with mindfulness treatment, $\beta=0.15, \mathrm{SE}=0.06, t=-3.38, N=1646, p<0.05$, increased challenge-seeking compared to the control group.

Additional measures. For additional results, see SM 5.5. As in Study 1, there was no increase in trait mindfulness; in fact, the growth mindset with mindfulness treatment reduced self-reported trait mindfulness immediately post-treatment, an effect we suspect may be due to response-shift bias (Howard, 1980): As people learn more about what mindfulness is, it may be more apparent that they are not yet enacting mindfulness. (Some suggest a response bias with regard to mindfulness may be particularly evident among adolescents whose metacognitive skills are not yet fully developed, see Goodman, Madni, Semple, 2017). There was no difference at the four-month follow-up.

In addition, there was an interesting pattern for students' self-reported maladaptive engagement with failures. While there were no differences by condition immediately post- 
treatment (as there as not in Study 1), at the follow-up, students reported being less likely to over-engage with failures and less likely to prematurely disengage from failure in both treatment conditions as compared to the control condition. 


\section{Table 2}

The (standardized) effects of the growth-mindset and growth-mindset with mindfulness interventions on first-semester high school GPA relative to the control condition (Study 2).

\begin{tabular}{|c|c|c|c|c|c|c|}
\hline & \multicolumn{3}{|c|}{ Sample $1(N=1853)$} & \multicolumn{3}{|c|}{ Sample $2(N=1445)$} \\
\hline Models & Base model & $\begin{array}{c}\text { Adding } \\
\text { random } \\
\text { school effect }\end{array}$ & $\begin{array}{c}\text { Adding } \\
\text { demographics }\end{array}$ & Base model & $\begin{array}{c}\text { Adding } \\
\text { random } \\
\text { school effect }\end{array}$ & $\begin{array}{c}\text { Adding } \\
\text { demographics }\end{array}$ \\
\hline Intercept & $\begin{array}{c}-0.82 * * * \\
(-0.92,-0.73)\end{array}$ & $\begin{array}{c}-0.76 * * * \\
(-0.87,-0.64)\end{array}$ & $\begin{array}{c}-0.70 * * * \\
(-0.83,-0.57)\end{array}$ & $\begin{array}{c}-.82 * * * \\
(-0.92,-0.72)\end{array}$ & $\begin{array}{c}-.77 * * * \\
(-0.90,-0.64)\end{array}$ & $\begin{array}{c}-.74 * * * \\
(-0.88,-0.59)\end{array}$ \\
\hline Growth-Mindset Intervention & $\begin{array}{c}0.13^{*} \\
(0.01,0.26)\end{array}$ & $\begin{array}{c}0.10 \dagger \\
(-0.02,0.23)\end{array}$ & $\begin{array}{c}0.10 \dagger \\
(-0.02,0.23)\end{array}$ & $\begin{array}{c}.13 \dagger \\
(-0.01,0.27)\end{array}$ & $\begin{array}{c}.11 \dagger \\
(-0.02,0.25)\end{array}$ & $\begin{array}{c}.11 \\
(-0.02,0.25)\end{array}$ \\
\hline $\begin{array}{l}\text { Growth-Mindset with } \\
\text { Mindfulness Intervention }\end{array}$ & $\begin{array}{c}0.18 * * \\
(0.05,0.31)\end{array}$ & $\begin{array}{c}0.18 * * \\
(0.06,0.31)\end{array}$ & $\begin{array}{c}0.17 * \\
(0.05,0.30)\end{array}$ & $\begin{array}{c}.19 * * \\
(0.04,0.33)\end{array}$ & $\begin{array}{c}.19 * * \\
(0.05,0.33)\end{array}$ & $\begin{array}{c}.19 * * \\
(0.05,0.33)\end{array}$ \\
\hline Prior GPA (centered -1 SD) & $\begin{array}{c}0.75^{* * *} \\
(0.68,0.81)\end{array}$ & $\begin{array}{c}0.68 * * * \\
(0.62,0.75)\end{array}$ & $\begin{array}{c}0.68 * * * \\
(0.61,0.74)\end{array}$ & $\begin{array}{c}.73 * * * \\
(0.66,0.80)\end{array}$ & $\begin{array}{c}.68 * * * \\
(0.61,0.76)\end{array}$ & $\begin{array}{c}.68 * * * \\
(0.61,0.76)\end{array}$ \\
\hline $\begin{array}{l}\text { Prior GPA } \times \text { Growth-Mindset } \\
\text { Intervention }\end{array}$ & $\begin{array}{c}-0.08 \dagger \\
(-0.17,0.01)\end{array}$ & $\begin{array}{c}-0.06 \\
(-0.15,0.02)\end{array}$ & $\begin{array}{c}-0.07 \\
(-0.15,0.02)\end{array}$ & $\begin{array}{c}-.05 \\
(-0.14,0.05)\end{array}$ & $\begin{array}{c}-.03 \\
(-0.12,0.06)\end{array}$ & $\begin{array}{c}-.04 \\
(-0.13,0.06)\end{array}$ \\
\hline $\begin{array}{l}\text { Prior GPA } \times \text { Growth-Mindset } \\
\text { with Mindfulness Intervention }\end{array}$ & $\begin{array}{c}-0.12^{* *} \\
(-0.21,-0.03)\end{array}$ & $\begin{array}{c}-0.12 * * \\
(-0.21,-0.03)\end{array}$ & $\begin{array}{c}-0.12^{* *} \\
(-0.21,-0.03)\end{array}$ & $\begin{array}{c}-.08^{*} \\
(-0.18,0.02)\end{array}$ & $\begin{array}{c}-.08 \dagger \\
(-0.17,0.01)\end{array}$ & $\begin{array}{c}-.08 \dagger \\
(-0.18,0.01)\end{array}$ \\
\hline Gender (female) & & & $\begin{array}{c}0.07 \\
(0.00,0.14)\end{array}$ & & & $\begin{array}{c}0.08 * \\
(0.00,0.16)\end{array}$ \\
\hline $\begin{array}{l}\text { Parents' post-secondary degree } \\
\text { (post-secondary degree) }\end{array}$ & & & $\begin{array}{c}-0.13 * * * \\
(-0.21,-0.06)\end{array}$ & & & $\begin{array}{c}-0.10 * * \\
(-0.18,-0.02)\end{array}$ \\
\hline Adjusted $\mathrm{R}^{2}$ & .43 & .44 & .45 & .46 & .49 & .49 \\
\hline
\end{tabular}

Note: OLS regressions. Standardized coefficients indicating standardized effect sizes; confidence intervals in parentheses. $\dagger$ p $<0.10$; $* p<0.05 ; * * p<0.01 ; * * * p<0.001$ 


\section{General Discussion}

Can we synthesize distinct yet complementary psychological interventions to form a coherent whole? Prior attempts to combine distinct mindset interventions have often simply paired existing treatments, one delivered after another in separate sessions. Some of these have produced little or no gain over the individual interventions (e.g., a growth-mindset and a prosocial purpose intervention, Paunesku et al., 2015; a growth-mindset and a social-belonging intervention, Yeager, Walton et al., 2016, Experiments 1 and 2). By contrast, in the present studies we carefully integrated mindfulness techniques into a growth-mindset intervention with the aim of helping students implement growth-mindset beliefs in the face of the negative thoughts and feelings that can arise in response to academic setbacks even when a person endorses a growth-mindset in general terms. Moreover, we delivered this integrated intervention in a culture in which high negative affect is prevalent (Eurostat, 2013, 2014).

In both field experiments, this enhanced growth-mindset treatment raised students' grades relative to a control condition. Moreover, in Study 2, which also included a growthmindset only condition, only the growth-mindset with mindfulness treatment produced reliable gains across models in the academic performance of students with a history of poor performance. The observed effect sizes of both treatments are in the range of the effects observed of similar online growth-mindset treatments in prior research (Paunesku et al., 2015; Yeager et al., 2019; Yeager, Walton et al., 2016; see Dweck \& Yeager, 2019) and, if anything, are somewhat larger for the treatment incorporating mindfulness. The mindset plus mindfulness intervention produced an effect size of 0.29 among mostly first-generation university students who were not especially high achieving in Study 1 and an effect size of 0.17-0.19 among lower-achieving students attending 47 different high schools in Study 2. The effect sizes in both studies fall at the 
upper end of the distribution of effect sizes for randomized controlled trials of educational interventions for adolescents with real-world outcomes that unfold over time (Kraft, 2020). As noted earlier, these effects are comparable to the effect of having a very good teacher rather than an average teacher for a year (Hanushek, 2011) or the gain that can be expected on nationally normed tests from a year of work in certain academic subjects (see Hill, Bloom, Black, \& Lipsey, 2008).

Importantly, the strengths and limitations of the two studies complement each other. Study 1 included a smaller sample but examined official academic records. Study 2 included a much larger and more diverse sample but examined self-reported grades. Nonetheless, this larger sample allowed us to examine moderation by prior performance level. As anticipated, the gains in GPA were concentrated among struggling students, consistent with past research (Paunesku et al., 2016; Yeager et al., 2019) — a finding of importance for both theory and application.

All psychological interventions take place in contexts; they help people contend with maladaptive ways of thinking that arise within those contexts and encourage more adaptive interpretations and narratives that they can appropriately apply in the same contexts (Walton \& Wilson, 2018; Walton \& Yeager, 2020). Indeed, as noted earlier, the present studies arose from our pilot work in Hungary, where we found that even Hungarians who fully endorsed a growth mindset reported experiencing negative thoughts and feelings about failures at least sometimes. We suggested that these reactions may be particularly likely in Hungary, where rates of negative emotions, including negative emotions about the self, are high (Eurostat, 2013, 2014). As mindfulness practices can help people contend with negative thoughts more effectively (Khoury et al., 2013), a mindful stance may be particularly important in this context. Yet studies have also noted a sharp rise in depression and anxiety among U.S. adolescents and college students over 
the last decade (Twenge, Cooper, Joiner, Duffy, \& Binau, 2019). It could be that a growth mindset plus mindfulness intervention may now also be advisable in the U.S. context. In any case, a critical direction for future research is to explore contextual factors, including through cross-cultural comparisons, to identify where mindfulness elements may enhance the effectiveness of growth-mindset interventions, or may even be necessary for benefits to occur, and where they are not necessary (cf. Canning, Muenks, Green, \& Murphy, 2019; Hanselman, Bruch, Gamoran, \& Borman, 2014; Walton, Logel, Peach, Spencer, \& Zanna, 2015; Walton \& Yeager, 2019; Yeager et al., 2019).

It is also exciting to consider whether mindfulness elements could strengthen interventions that provide adaptive ways of thinking about other kinds of challenges. For instance, social-belonging interventions convey that it is normal to worry at first about belonging during an academic transition but that this improves with time (Walton \& Brady, 2020b). Such interventions can prevent globalized feelings of nonbelonging in response to negative daily events, such as perceived exclusion by peers or a brusque interaction with an instructor (Walton \& Cohen, 2011). Could mindfulness techniques be integrated effectively with this approach, and thus help students recognize, accept, and let go of passing feelings of nonbelonging when they arise? Theory-of-personality interventions convey that people can change and, thus, that bullies need not always be bullies and victims need not always be victims (Yeager et al., 2014). Could mindfulness techniques be integrated with this approach, and help students recognize, accept, and let go of negative self-directed feelings of rejection or victimization and thereby be able to implement the teachings of the intervention more effectively? Introducing the idea of brief, targeted mindfulness training opens the door to designing mindfulness supplements for a widerange of existing psychologically "wise" interventions. Such interventions often provide adaptive 
and non-pejorative narratives for people to make sense of challenges they face (Walton \& Brady, 2020a; Walton \& Wilson, 2018). Perhaps mindfulness elements can help people effectively process contrary nagging negative thoughts and feelings that arise nevertheless, be they academic setbacks, social rejections, or work stress, in a manner that works synergistically with the base intervention.

As these examples suggest, another important direction for future research is to further understand the change in psychological processes brought about by the integration of mindset and mindfulness and, specifically, how these elements may separately and together alter the moment-to-moment processing and experiencing of negative thoughts and feelings following an intervention. In Study 1, it was intriguing that the growth-mindset + mindfulness treatment led students, immediately after treatment, to report that they intended to use a mindful stance more in response to academic setbacks, felt more confident in their ability to do so, and viewed mindfulness as more malleable rather than as a fixed trait or ability. Moreover, the final measure assessing the perceived malleability vs. fixedness of mindfulness, marginally statistically mediated the gain in GPA. Yet these measures have not yet been validated and do not assess how people actually respond to academic setbacks. Future laboratory and field research may explore whether people are actually better able to recognize, accept, and let go of negative thoughts and feelings with a mindset treatment that includes mindfulness elements and how this plays out over time. Does the letting go of negative thoughts and feelings become more automatic with practice, such that physiological measures show shorter and milder episodes of negative affect given the same magnitude of setback? The present research suggests the potential power of the synthesis between mindsets and mindfulness and the importance of future research examining the processes that it engenders. 


\section{References}

Aronson, J., Fried, C. B., \& Good, C. (2002). Reducing the effects of stereotype threat on African American college students by shaping theories of intelligence. Journal of Experimental Social Psychology, 38(2), 113-125. doi: 10.1006/jesp.2001.1491

Beaton, D. E., Bombardier, C., Guillemin, F., \& Ferraz, M. B. (2000). Guidelines for the process of cross-cultural adaptation of self-report measures. Spine, 25(24), 3186-3191. doi: $10.1097 / 00007632-200012150-00014$

Bettinger, E. P., Ludvigsen, S., Rege, M., Solli, I. F., \& Yeager, D. S. (2018). Increasing perseverance in math: Evidence from a field experiment in Norway. Journal of Economic Behavior \& Organization, 146, 1-15. doi: 10.1016/j.jebo.2017.11.032

Blackwell, L. S., Trzesniewski, K. H., \& Dweck, C. S. (2007). Implicit theories of intelligence predict achievement across an adolescent transition: A longitudinal study and an intervention. Child Development, 78(1), 246-263. doi: 10.1111/j.14678624.2007.00995.x

Burnette, J. L., O'Boyle, E. H., VanEpps, E. M., Pollack, J. M., \& Finkel, E. J. (2013). Mind-sets matter: A meta-analytic review of implicit theories and self-regulation. Psychological Bulletin, 139(3), 655-701. doi: 10.1037/a0029531

Canning, E. A., Muenks, K., Green, D. J., \& Murphy M. C. (2019). STEM faculty who believe ability is fixed have larger racial achievement gaps and inspire less student motivation in their classes. Science Advances, 5(2), eaau4734. doi: 10.1126/sciadv.aau4734

Chiesa, A., Calati, R., \& Serretti, A. (2011). Does mindfulness training improve cognitive abilities? A systematic review of neuropsychological findings. Clinical Psychology Review, 31(3), 449-464. doi: 10.1016/j.cpr.2010.11.003 
Creswell, J. D. (2017). Mindfulness interventions. Annual Review of Psychology, 68, 491-516. doi: 10.1146/annurev-psych-042716-051139

Crum, A. J., Salovey, P., \& Achor, S. (2013). Rethinking stress: The role of mindsets in determining the stress response. Journal of Personality and Social Psychology, 104(4), 716-733. doi: 10.1037/a0031201

Dweck, C. (2015). Carol Dweck revisits the growth mindset. Education Week, 35(5), 20-24.

Dweck, C. S. (2016). Mindset: The New Psychology of Success. (Updated edition). New York: Random House.

Dweck, C. S., Chiu, C. Y., \& Hong, Y. Y. (1995). Implicit theories and their role in judgments and reactions: A word from two perspectives. Psychological Inquiry, 6(4), 267-285. doi: $10.1037 / \mathrm{a} 0029531$

Dweck, C.S., \& Yeager, D.S. (2019). Mindsets: A view from two eras. Perspectives on Psychological Science, 14(3), 481-496. doi: 10.1177/1745691618804166

Eberth, J., \& Sedlmeier, P. (2012). The effects of mindfulness meditation: A meta-analysis. Mindfulness, 3(3), 174-189. doi: 10.1007/s12671-012-0101-х

Eurostat. (2013). Quality of Life, Facts and Views. Retrieved July 1, 2019. https://bit.ly/2NnHeVh

Eurostat. (2014). Current depressive symptoms by sex, age and educational attainment level. Retrieved July 1, 2019. http://appsso.eurostat.ec.europa.eu/nui/submitViewTableAction.do

Feldman, G., Hayes, A., Kumar, S., Greeson, J., \& Laurenceau, J. P. (2007). Mindfulness and emotion regulation: The development and initial validation of the Cognitive and 
Affective Mindfulness Scale-Revised (CAMS-R). Journal of Psychopathology and Behavioral Assessment, 29(3), 177-195. doi: 10.1007/s10862-006-9035-8

Goodman, M. S., Madni, L. A., \& Semple, R. J. (2017). Measuring mindfulness in youth: Review of current assessments, challenges, and future directions. Mindfulness, 8(6), 1409-1420. 10.1007/s12671-017-0719-9

Gunderson, E. A., Gripshover, S. J., Romero, C., Dweck, C. S., Goldin-Meadow, S., \& Levine, S. C. (2013). Parent praise to 1-to 3-year-olds predicts children's motivational frameworks 5 years later. Child Development, 84(5), 1526-1541. doi:

10.1111/cdev.12064

Hanselman, P., Bruch, S. K., Gamoran, A., \& Borman, G. D. (2014). Threat in context: School moderation of the impact of social identity threat on racial/ethnic achievement gaps. Sociology of Education, 87(2), 106-124. doi: 10.1177/0038040714525970

Hanushek, E. A. (2011). The economic value of higher teacher quality. Economics of Education review, 30(3), 466-479. doi: 10.1016/j.econedurev.2010.12.006

Hill, C. J., Bloom, H. S., Black, A. R., \& Lipsey, M. W. (2008). Empirical benchmarks for interpreting effect sizes in research. Child Development Perspectives, 2(3), 172-177. doi: 10.1111/j.1750-8606.2008.00061.x

Hofmann, S. G., Sawyer, A. T., Witt, A. A., \& Oh, D. (2010). The effect of mindfulness-based therapy on anxiety and depression: A meta-analytic review. Journal of Consulting and Clinical Psychology, 78(2), 169-183. doi: 10.1037/a0018555

Howard, G. S. (1980). Response-Shift Bias. Evaluation Review, 4(1), 93-106. doi:10.1177/0193841x8000400105 
Kabat-Zinn, J. (1982). An outpatient program in behavioral medicine for chronic pain patients based on the practice of mindfulness meditation: Theoretical considerations and preliminary results. General hospital psychiatry, 4(1), 33-47.

Kabat-Zinn, J. (2003). Mindfulness-based interventions in context: past, present, and future. Clinical psychology: Science and Practice, 10(2), 144-156. doi: 10.1093/clipsy/bpg016

Kamins, M. L., \& Dweck, C. S. (1999). Person versus process praise and criticism: Implications for contingent self-worth and coping. Developmental Psychology, 35(3), 835-847. doi: $10.1016 / \mathrm{S} 1060-3743(01) 00038-8$

Khoury, B., Lecomte, T., Fortin, G., Masse, M., Therien, P., Bouchard, V., Chapeleau, M. A., Paquin, K., \& Hofmann, S. G. (2013). Mindfulness-based therapy: a comprehensive meta-analysis. Clinical Psychology Review, 33(6), 763-771. doi: 10.1016/j.cpr.2013.05.005

Kuncel, N. R., Credé, M., \& Thomas, L. L. (2005). The validity of self-reported grade point averages, class ranks, and test scores: A meta-analysis and review of the literature. Review of Educational Research, 75(1), 63-82.

Kraft, M. A. (2020). Interpreting effect sizes of education interventions. Educational Researcher. doi: 10.3102/0013189X20912798

Kross, E., Ayduk, O., \& Mischel, W. (2005). When asking “why” does not hurt distinguishing rumination from reflective processing of negative emotions. Psychological Science, 16(9), 709-715. doi: 10.1111/j.1467-9280.2005.01600.x

Kross, E., Bruehlman-Senecal, E., Park, J., Burson, A., Dougherty, A., Shablack, H., ... \& Ayduk, O. (2014). Self-talk as a regulatory mechanism: how you do it matters. Journal of Personality and Social Psychology, 106(2), 304-324. doi: 10.1037/a0035173 
Lindsay, E. K., \& Creswell, J. D. (2017). Mechanisms of mindfulness training: Monitor and Acceptance Theory (MAT). Clinical Psychology Review, 51, 48-59. doi: 10.1016/j.cpr.2016.10.011

Mueller, C. M., \& Dweck, C. S. (1998). Praise for intelligence can undermine children's motivation and performance. Journal of Personality and Social Psychology, 75(1), 33-52. doi: 0022-3514/98

Murphy, M. C., \& Dweck, C. S. (2010). A culture of genius: How an organization's lay theory shapes people's cognition, affect, and behavior. Personality and Social Psychology Bulletin, 36(3), 283-296. doi: 10.1177/0146167209347380

Neff, K. D., Hsieh, Y. P., \& Dejitterat, K. (2005). Self-compassion, achievement goals, and coping with academic failure. Self and Identity, 4(3), 263-287. doi: $10.1080 / 13576500444000317$

Nussbaum, A. D., \& Dweck, C. S. (2008). Defensiveness versus remediation: Self-theories and modes of self-esteem maintenance. Personality and Social Psychology Bulletin, 34(5), 599-612. doi: 10.1177/0146167207312960

Orosz, G., Péter-Szarka, Sz., Bőthe, B., Tóth-Király, I., \& Berger, R. (2017). How Not to Do a Mindset Intervention: Learning from a Mindset Intervention among Students with Good Grades. Frontiers in Psychology, 8:311. doi: 10.3389/fpsyg.2017.00311

Papies, E. K., Barsalou, L. W., \& Custers, R. (2012). Mindful attention prevents mindless impulses. Social Psychological and Personality Science, 3(3), 291-299. doi: $10.1177 / 1948550611419031$

Papies, E. K., Pronk, T. M., Keesman, M., \& Barsalou, L. W. (2015). The benefits of simply observing: Mindful attention modulates the link between motivation and 
behavior. Journal of Personality and Social Psychology, 108(1), 148-171. doi:

$10.1037 / \mathrm{a} 0038032$

Paunesku, D., Walton, G. M., Romero, C., Smith, E. N., Yeager, D. S., \& Dweck, C. S. (2015). Mind-set interventions are a scalable treatment for academic underachievement. Psychological Science, 26(6), 784-793. doi: 10.1177/0956797615571017

OECD (2017). PISA 2015 Results (Volume III): Students' Well-Being. Paris: OECD Publishing. doi:10.1787/9789264273856-en

Outes, I., Sánchez, A., \& Vakis, R. (2017). Cambiando la mentalidad de los estudiantes: evaluación de impacto de ;Expande tu Mente! sobre el rendimiento académico en tres regiones del Perú (No. 83; pp. 1-106). Retrieved from Grupo de Análisis para el Desarrollo website: http://www.grade.org.pe/wp-content/uploads/ddt83.pdf

Pomerantz, E. M., \& Kempner, S. G. (2013). Mothers' daily person and process praise: Implications for children's theory of intelligence and motivation. Developmental Psychology, 49(11), 2040-2046. doi: 10.1037/a0031840

Rihmer, Z., Gonda, X., Kapitany, B., \& Dome, P. (2013). Suicide in Hungary-epidemiological and clinical perspectives. Annals of General Psychiatry, 12(1), 21. doi: 10.1186/1744$859 X-12-21$

Robins R. W. \& Pals J. L. (2002): Implicit Self-Theories in the Academic Domain: Implications for Goal Orientation, Attributions, Affect, and Self-Esteem Change, Self and Identity, 1(4), 313-336. doi: 10.1080/15298860290106805

Shepherd, D. A., \& Cardon, M. S. (2009). Negative emotional reactions to project failure and the self-compassion to learn from the experience. Journal of Management Studies, 46(6), 923-949. doi: 10.1111/j.1467-6486.2009.00821.x 
Steele, C. M., \& Aronson, J. (1995). Stereotype threat and the intellectual test performance of African Americans. Journal of Personality and Social Psychology, 69(5), 797-811.

Strick, M., \& Papies, E. K. (2017). A brief mindfulness exercise promotes the correspondence between the implicit affiliation motive and goal setting. Personality and Social Psychology Bulletin, 43(5), 623-637. doi: 10.1177/0146167217693611

Twenge, J. M., Cooper, A. B., Joiner, T. E., Duffy, M. E., \& Binau, S. G. (2019). Age, period, and cohort trends in mood disorder indicators and suicide-related outcomes in a nationally representative dataset, 2005-2017. Journal of Abnormal Psychology, 128(3), 185-199. doi:10.1037/abn0000410

Walton, G. M. \& Brady, S. T. (2020a). “Bad” things reconsidered. In J. P. Forgas, K. Fiedler, \& W. D. Crano (Eds.) Sydney Symposium of Social Psychology: Applications of Social Psychology. Routledge: New York.

Walton, G. M., Brady S. T. (2020b). The social-belonging intervention. In G. M. Walton \& A. J. Crum (Eds.) Handbook of Wise Interventions: How Social-Psychological Insights Can Help People Change, Guilford Press: New York, NY.

Walton, G. M. \& Crum, A. J. (Eds.) (2020). Handbook of Wise Interventions: How Social Psychology Can Help People Change. Guilford Press: New York.

Walton, G. M., \& Cohen, G. L. (2011). A brief social-belonging intervention improves academic and health outcomes of minority students. Science, 331(6023), 1447-1451. doi: 10.1126/science. 1198364

Walton, G. M., Logel, C., Peach, J. M., Spencer, S. J., \& Zanna, M. P. (2015). Two brief interventions to mitigate a "chilly climate" transform women's experience, relationships, 
and achievement in engineering. Journal of Educational Psychology, 107(2), 468-485. doi: $10.1037 / \mathrm{a} 0037461$

Walton, G. M., Yeager, D. S. (2020). Seed and Soil: Psychological Affordances in Contexts Explain Where Wise Interventions Succeed or Fail. Current Directions in Psychological Science, 29, 219-226. doi: 10.1177/0963721420904453

Walton, G. M., \& Wilson, T. D. (2018). Wise interventions: Psychological remedies for social and personal problems. Psychological Review, 125(5), 617-655. doi: 10.1037/rev0000115

Yeager, D. S., Johnson, R., Spitzer, B. J., Trzesniewski, K. H., Powers, J., \& Dweck, C. S. (2014). The far-reaching effects of believing people can change: Implicit theories of personality shape stress, health, and achievement during adolescence. Journal of Personality and Social Psychology, 106(6), 867-884. doi: 10.1037/a0036335

Yeager, D. S., Hanselman, P., Walton, G. M., Murray, J. S., Crosnoe, R., Muller, C., ... \& Paunesku, D. (2019). A national experiment reveals where a growth mindset improves achievement. Nature, 573(7774), 364-369. doi: 10.1038/s41586-019-1466-y

Yeager, D. S., Romero, C., Paunesku, D., Hulleman, C. S., Schneider, B., Hinojosa, C., ... \& Trott, J., Greene, D., Walton, G. M., \& Dweck, C. (2016). Using design thinking to improve psychological interventions: The case of the growth mindset during the transition to high school. Journal of Educational Psychology, 108(3), 374-391. doi: 10.1037/edu0000098

Yeager, D. S., Walton, G. M., Brady, S. T., Akcinar, E. N., Paunesku, D., Keane, L., Kamentz, D., Ritter, G., Duckworth, A. L., Urstein, R., Gomez E., Markus, H. R. Cohen, G. L., \& Dweck, C. S. (2016). Teaching a lay theory before college narrows achievement gaps at 
scale. Proceedings of the National Academy of Sciences, 113(24), 3341-3348. doi:

$10.1073 /$ pnas. 1524360113

Zenner, C., Herrnleben-Kurz, S., \& Walach, H. (2014). Mindfulness-based interventions in schools - a systematic review and meta-analysis. Frontiers in Psychology, 5(603), 1-20. doi: $10.3389 /$ fpsyg.2014.00603 